
tino. Horticultura Brasileira 26:097-101.

\title{
Avaliação de genótipos de cebola no Semi-Árido Nordestino
}

\author{
Jean de O Souzaㄹ; Leilson C Grangeiro후; Gilmara Mabel Santos²; Nivaldo Duarte Costa²; Carlos Antônio \\ F Santos'; Glauber Henrique de S Nunes ${ }^{1}$
}

${ }^{1}$ UFERSA, Depto. Ciências Vegetais, C. postal 137, 59625-900 Mossoró-RN; ²Embrapa Semi-Árido, C. postal 23, 56302-970 PetrolinaPE; leilson@ufersa.edu.br

\begin{abstract}
RESUMO
Neste trabalho foi avaliado o desempenho produtivo de genótipos de cebola no Semi-Árido Nordestino. Foram conduzidos, simultaneamente, experimentos em três locais (Mossoró-RN, Petrolina-PE e Juazeiro-BA), de maio a setembro de 2004. Os delineamentos foram em blocos completos casualizados, com três repetições. Os tratamentos foram constituídos pelos genótipos de cebola: CNPH 6415, CNPH 6047, CNPH 6244, CNPH 6400 Chata, CNPH 6400 Redonda, CPACT 1, CPACT 2, CPACT 3, Granex 429, Belém IPA 9, BRS Cascata, Crioula Alto Vale, Bola Precoce, Primavera, Régia, Valeouro IPA-11, Brisa e Alfa São Francisco. Foram avaliados o peso médio de bulbos comerciais, produtividades total, comercial e não comercial de bulbos. Os genótipos com os melhores desempenhos produtivos foram: Brisa (59,8 t ha ${ }^{-1}$ ) em Mossoró, Belém IPA-9 (58,9 t $\left.h^{-1}\right)$, Régia (58,9 t ha-1) em Petrolina e Granex 429 (27,9 t ha-1), Brisa (26,6 t ha $\left.{ }^{-1}\right)$, Alfa São Francisco (23,0 t ha-1) e Régia (20,0 t ha $\left.{ }^{1}\right)$ em Juazeiro.
\end{abstract}

Palavras-chave: Allium cepa, rendimento de bulbos, adaptação.

\begin{abstract}
Yield of onion genotypes in the semi arid region of Northeastern Brazil

The yield performance of onion genotypes was evaluated in the semi arid region of Northeastern Brazil. The experiments were carried out in counties of different Northeastern States [Mossoró (Rio Grande do Norte), Petrolina (Pernambuco) and Juazeiro (Bahia)], from May to September, 2004. The experimental design was of randomized complete blocks with eighteen treatments and three replications. The treatments consisted of the following onion genotypes: CNPH 6415, CNPH 6047, CNPH 6244, CNPH 6400 Chata, CNPH 6400 Redonda, CPACT 1, CPACT 2, CPACT 3, Granex 429, Belém IPA 9, BRS Cascata, Crioula Alto Vale, Bola Precoce, Primavera, Régia, Valeouro IPA-11, Brisa and Alfa São Francisco. Commercial bulb mean weight and total, commercial and non commercial bulb yield were evaluated. The highest yields were obtained from the cultivars: Brisa (59,8 $\mathrm{t}$ ha $^{-1}$ ) in Mossoró, Belém IPA-9 (58,9 t ha-1), Régia (58,9 t ha $\left.{ }^{-1}\right)$ in Petrolina and Granex 429 (27,9 t ha-1), Brisa (26,6 t ha' $\left.\mathrm{t}^{-1}\right)$, Alfa São Francisco (23,0 tha $\left.{ }^{-1}\right)$ and Régia (20,0 $\left.\mathrm{t} \mathrm{ha}^{-1}\right)$ in Juazeiro.
\end{abstract}

Keywords: Allium cepa, yield, adaptation.

(Recebido para publicação em 23 de abril de 2007; aceito em 13 de fevereiro de 2008)

A produção mundial de cebola em 2004 foi de 53,6 milhões de toneladas, cultivadas em uma área de 3,07 milhões de hectares, o que proporcionou uma produtividade média de 17,46 t ha-1 (FAO, 2005). No Brasil, a cebola ocupa o terceiro lugar em importância econômica entre as hortaliças, com produtividade média de 17,88 t ha-1 ${ }^{-1}$ A região Nordeste, devido às condições edafoclimáticas, oferece grandes vantagens comparativas às demais regiões produtoras de cebola do país, uma vez que permite o plantio durante todo o ano. Os estados de Pernambuco e Bahia, maiores produtores do Nordeste, respondem por 99,0\% da produção regional, que por sua vez correspondem a 18,2\% da produção brasileira, com produtividade média de 21,2 e 24,3 t ha-1 , respectivamente (IBGE, 2005).

O melhoramento genético de cebola no Nordeste vem sendo executado desde 1972, ininterruptamente até o presente e contempla as cebolas roxas e amarelas, com o objetivo de desenvolver cultivares dotadas de elevado potencial produtivo, nível elevado de tolerância ao tripes (Thrips tabaci) e resistência ao mal-de-sete-voltas (Collectrotrichum gloeosporioides) (Candeia et al., 1997) e a raiz rosada (Pyrenochaeta terrestris), considerados os principais problemas fitossanitários da região, além de melhor conservação pós-colheita (Candeia et al., 1987), pungência moderada (Costa et al., 2003) e boa adaptação às condições ambientais locais.

Ao longo desses anos, uma série de cultivares foi desenvolvida na região por instituições, como a Empresa Pernambucana de Pesquisa (IPA) em parceria com a Embrapa Semi-Árido e Embrapa Hortaliças, com destaque às da série IPA, Alfa Tropical e Alfa São Francisco. Também foram realizados estudos de adaptação de cultivares com o objetivo de selecionar aquelas mais produtivas, resistentes às principais doen- ças e pragas e boa aceitação pelo consumidor.

Estudos de adaptação de cultivares de cebola nas condições do Vale Submédio São Francisco foram realizados por Costa et al. (2000) que verificaram produtividade de bulbos comerciais variando de 21,4 a 61,8 t ha-1, destacando-se as cultivares Granex 429, Texas Grano 502, Fransciscana IPA-10 e Vale Ouro IPA-11. No experimento realizado por Candeia et al. (2001) em Pernambuco, as cultivares Texas Grano 502 PRR e Texas Grano 1015Y destacaram-se com produtividades de 54,8 e 54,2 $\mathrm{t} \mathrm{ha}^{-1}$, respectivamente. Em Juazeiro, Costa et al. (2003) obtiveram produtividades comerciais variando de 33,5 a 61,1 t ha-1, com o híbrido experimental TPC-91923 destacando-se dos demais.

Em experimento mais recente realizado por Leite et al. (2005) no Vale do São Francisco, a produtividade comercial de cebola foi superior à média da 
Tabela 1. Características dos 18 genótipos de cebola avaliados em Mossoró, Petrolina e Juazeiro (Characteristics of 18 onion genotypes, evaluated in Mossoró, Petrolina and Juazeiro). Mossoró, UFERSA, 2004.

\begin{tabular}{|c|c|c|c|}
\hline Genótipos & Procedência (empresa) & Tipo (fotoperíodo) & Ciclo de maturação (dias) \\
\hline $\begin{array}{l}\text { CNPH } 6415 \text { (Baia do Cedo x Baia Per. Super Precoce } \\
\text { x IPA1 x IPA } 2 \text { x IPA } 3 \text { x Pira Tropical) (L) }\end{array}$ & Embrapa Hortaliças & Dias curtos & Precoce/150-170 \\
\hline CNPH 6047 (Baia Periforme x Crioula) (L) & Embrapa Hortaliças & Dias curtos & Precoce/150-170 \\
\hline $\begin{array}{l}\text { CNPH } 6244 \text { (Seleção em Baia Periforme super } \\
\text { precoce) (OP) }\end{array}$ & Embrapa Hortaliças & Dias curtos & Precoce/150-170 \\
\hline CNPH 6400 Chata (BaiaPeriforme x Valcatorce) (L) & Embrapa Hortaliças & Dias curtos & Precoce/150-170 \\
\hline CNPH 6400 Redonda (Baia Periforme x Valcatorce) (L) & Embrapa Hortaliças & Dias curtos & Precoce/150-170 \\
\hline CPACT 1(Pera Norte x Primavera) (L) & Embrapa Clima Temperado & Dias intermediários & Precoce/125-140 \\
\hline CPACT 2 (Primavera x Pera Norte) $(L)$ & Embrapa Clima Temperado & Dias intermediários & Precoce/125-140 \\
\hline CPACT 3 (Valencianita x Aurora) (L) & Embrapa Clima Temperado & Dias intermediários & Super Precoce/110-125 \\
\hline Granex $429(H)$ & SVS & Dias curtos & Super precoce/110-160 \\
\hline Belém IPA 9 (OP) & IPA & Dias curtos & Precoce/150-170 \\
\hline BRS Cascata (OP) & Embrapa Clima Temperado & Dias intermediários & Médio/180-210 \\
\hline Crioula Alto Vale (EPAGRI 362/OP) & EPAGRI & Dias intermediários & Tardio/190-240 \\
\hline Bola Precoce (EMPASC 352/OP) & EPAGRI & Dias intermediários & Médio/170-190 \\
\hline Primavera (OP) & Embrapa Clima Temperado & Dias intermediários & Precoce/150-170 \\
\hline Régia (OP) & SVS & Dias curtos & Precoce/150-170 \\
\hline Valeouro IPA 11 (Roxa IPA-3 x Belém IPA-9) (L) & IPA & Dias curtos & Super precoce/120-140 \\
\hline Brisa (Roxa IPA-3 x Texas Grano 1015Y) (L) & IPA & Dias curtos & Super precoce/120-140 \\
\hline Alfa São Francisco (Seleção em Alfa Tropical) (OP) & Embrapa Semi-Árido & Dias curtos & Precoce/150-170 \\
\hline
\end{tabular}

OP: Cultivar de polinização aberta (OP: open pollination cultivar), H: Híbrido (H: hybrid), L: Linhagem.

região, oscilando entre 24,0 e 56,0 t ha-1, sobressaindo-se as cultivares EX07593000 (55,2 t ha $\left.^{-1}\right)$, Granex 429 (56,0 $\left.\mathrm{t} \mathrm{ha}^{-1}\right)$, IPA 11 (51,3 t ha-1), IPA 4 (47,9 t ha $\left.^{-1}\right)$, Texas Grano 502 (47,1 t ha-1) e Brisa (41,9 t ha-1). O presente trabalho teve por objetivo avaliar o desempenho produtivo de dezoito genótipos de cebola no Semi-Árido Nordestino, para identificar os mais adaptados em cada região de estudo.

\section{MATERIAL E MÉTODOS}

Os experimentos foram conduzidos de maio a setembro de 2004, simultaneamente em três locais: em área experimental da UFERSA em Mossoró, em solo classificado como Argissolo Vermelho Amarelo; em campo experimental da Embrapa Semi-Árido em Petrolina, em solo classificado como Latossolo Vermelho Amarelo, textura arenosa e, o terceiro em campo experimental da Embrapa Semi-Árido em Juazeiro, em solo classificado como Vertissolo. Das áreas experimentais foram coletadas amostras de solos ( 0 - 0,3 $\mathrm{m})$, cujos resultados das análises foram: Em Mossoró, pH (água 1: 2,5) = 7,5; $\mathrm{Ca}=5,20 \mathrm{cmol}_{\mathrm{c}} \mathrm{dm}^{-3} ; \mathrm{Mg}=0,60 \mathrm{cmol}_{\mathrm{c}}$ $\mathrm{dm}^{-3} ; \mathrm{K}=0,41 \mathrm{cmol}_{\mathrm{c}} \mathrm{dm}^{-3} ; \mathrm{Na}=0,08$ $\mathrm{cmol}_{\mathrm{c}} \mathrm{dm}^{-3} ; \mathrm{Al}=0,00 \mathrm{cmol}_{\mathrm{c}} \mathrm{dm}^{-3}$ e P = $146 \mathrm{mg} \mathrm{dm}^{-3}$; Em Petrolina, pH (água 1: 2,5) = 7,0; $\mathrm{Ca}=2,20 \mathrm{cmol}_{\mathrm{c}} \mathrm{dm}^{-3} ; \mathrm{Mg}$ $=0,80 \mathrm{cmol}_{\mathrm{c}} \mathrm{dm}^{-3} ; \mathrm{K}=0,32 \mathrm{cmol}_{\mathrm{c}} \mathrm{dm}^{-3}$; $\mathrm{Na}=0,05 \mathrm{cmol}_{\mathrm{c}} \mathrm{dm}^{-3} ; \mathrm{Al}=0,05 \mathrm{cmol}_{c}$ $\mathrm{dm}^{-3}$ e $\mathrm{P}=23,8 \mathrm{mg} \mathrm{dm}^{-3}$; Em Juazeiro, pH (água 1: 2,5) = 8,3; $\mathrm{Ca}=30,0 \mathrm{cmol}_{\mathrm{c}}$ $\mathrm{dm}^{-3} ; \mathrm{Mg}=1,90 \mathrm{cmol} \mathrm{dm}^{-3} ; \mathrm{K}=0,34$ $\mathrm{cmol}_{\mathrm{c}} \mathrm{dm}^{-3} ; \mathrm{Na}=0,09 \mathrm{cmol}_{\mathrm{c}} \mathrm{dm}^{-3} ; \mathrm{Al}=$ $0,00 \mathrm{cmol}_{\mathrm{c}} \mathrm{dm}^{-3}$ e P $=35,0 \mathrm{mg} \mathrm{dm}^{-3}$.

O preparo do solo constou de uma aração a 0,30 m de profundidade, seguida de gradagem, e levantamento dos canteiros. As adubações foram realizadas com base na análise do solo e segundo recomendação de Cavalcanti (1998), sendo utilizados em Mossoró, $45 \mathrm{~kg} \mathrm{ha}^{-1}$ de $\mathrm{N}, 45 \mathrm{~kg} \mathrm{ha}^{-1}$ de $\mathrm{P}_{2} \mathrm{O}_{5}$ e $45 \mathrm{~kg} \mathrm{ha}^{-1}$ de $\mathrm{K}_{2} \mathrm{O}$, nas formas de uréia, superfosfato simples e cloreto de potássio respectivamente. Nos experimentos realizados em Petrolina e Juazeiro usaram-se $600 \mathrm{~kg} \mathrm{ha}^{-1}$ da fórmula 06-24-12.

As mudas foram produzidas em sementeiras com dimensões de $1 \mathrm{~m}$ de largura e 0,20 m de altura, cujo preparo consistiu de aração, gradagem e sulcamento. Utilizou-se $10 \mathrm{~g} \mathrm{~m}^{-2}$ de sementes para semeadura em sulcos transversais ao comprimento do canteiro, com profundidade de 0,01 m e distância entre sulcos de $0,10 \mathrm{~m}$. O sistema de irrigação utilizado foi microaspersão, com freqüência diária e lâmina de irrigação de modo a manter sempre a capacidade de campo.

O transplantio foi realizado 39 dias após a semeadura (10/05/04) quando as mudas atingiram 0,15 a $0,20 \mathrm{~m}$ de altura. Após o transplantio foi aplicado o herbicida oxadiazon na dose de $1 \mathrm{~kg} \mathrm{ha}^{-1}$ (i.a.) para controlar as plantas daninhas na fase inicial do ciclo da cultura, em seguida foram adotados tratos culturais como capinas manuais e aplicações preventivas de defensivos para o controle de pragas e doenças com produtos registrados para a cultura.

Em adubação de cobertura, no experimento de Mossoró utilizaram-se 100 $\mathrm{kg} \mathrm{ha}^{-1}$ de N (uréia), parcelados em três aplicações (20, 35 e 50 dias após o transplantio) e $50 \mathrm{~kg} \mathrm{ha}^{-1}$ de $\mathrm{K}_{2} \mathrm{O}$ (cloreto de potássio), parcelados em duas aplicações aos 45 e 60 dias após o transplantio. Nos experimentos de Petrolina e Juazeiro foram utilizados 55 $\mathrm{kg} \mathrm{ha}^{-1}$ de $\mathrm{N}$ na forma de uréia parcelados em três aplicações (25, 40 e 50 dias após o transplantio) e $42 \mathrm{~kg} \mathrm{ha}^{-1}$ de $\mathrm{K}_{2} \mathrm{O}$ na forma de cloreto de potássio, em duas 
Tabela 2. Valores médios das produtividades total, comercial e não comercial de bulbos de 18 genótipos de cebola avaliados em Mossoró, Petrolina e Juazeiro (Mean values of total, commercial and non commercial yield of 18 onion genotypes in Mossoró, Petrolina and Juazeiro). Mossoró, UFERSA, 2004.

\begin{tabular}{|c|c|c|c|c|c|c|c|c|c|}
\hline \multirow{3}{*}{ Genótipos } & \multicolumn{9}{|c|}{ Produtividade $\left(\mathrm{t} \mathrm{ha} \mathrm{a}^{-1}\right)$} \\
\hline & \multicolumn{3}{|c|}{ Total } & \multicolumn{3}{|c|}{ Comercial } & \multicolumn{3}{|c|}{ Não comercial } \\
\hline & Mossoró & Petrolina & Juazeiro & Mossoró & Petrolina & Juazeiro & Mossoró & Petrolina & Juazeiro \\
\hline CNPH 6415 & $28,04 \mathrm{Bc}$ & $37,41 \mathrm{Ac}$ & $22,57 \mathrm{Bb}$ & $27,36 \mathrm{Ac}$ & $29,90 \mathrm{Ac}$ & $18,24 \mathrm{Bb}$ & $0,68 \mathrm{Cb}$ & $7,51 \mathrm{Aa}$ & $4,33 \mathrm{Bb}$ \\
\hline CNPH 6047 & $51,53 \mathrm{Ab}$ & $51,02 \mathrm{Ab}$ & $19,13 \mathrm{Bb}$ & $51,37 \mathrm{Ab}$ & $48,01 \mathrm{Ab}$ & $14,69 \mathrm{Bb}$ & $0,16 \mathrm{Cc}$ & $3,01 \mathrm{Bc}$ & 4,44 Aa \\
\hline Granex 429 & $35,08 \mathrm{Bc}$ & $44,25 \mathrm{Ab}$ & $29,85 \mathrm{Ba}$ & $34,55 \mathrm{Ac}$ & $41,00 \mathrm{Ab}$ & $27,91 \mathrm{Ba}$ & $0,53 \mathrm{Bc}$ & $3,25 \mathrm{Ac}$ & $1,94 \mathrm{Ac}$ \\
\hline CNPH 6244 & $48,97 \mathrm{Ab}$ & $22,24 \mathrm{Bd}$ & $12,38 \mathrm{Cc}$ & $48,17 \mathrm{Ab}$ & $17,98 \mathrm{Bd}$ & $6,94 \mathrm{Cc}$ & $0,80 \mathrm{Bb}$ & $4,26 \mathrm{Ac}$ & $5,44 \mathrm{Aa}$ \\
\hline BRS Cascata & $30,09 \mathrm{Bc}$ & $39,82 \mathrm{Ac}$ & $9,41 \mathrm{Cc}$ & $28,07 \mathrm{Ac}$ & $33,82 \mathrm{Ac}$ & $2,47 \mathrm{Bc}$ & $2,02 \mathrm{Ba}$ & $6,00 \mathrm{Ab}$ & 6,94 Aa \\
\hline СРАСТ 1 & $25,09 \mathrm{Bc}$ & $37,52 \mathrm{Ac}$ & $11,09 \mathrm{Cc}$ & $24,45 \mathrm{Ac}$ & $30,46 \mathrm{Ac}$ & $5,54 \mathrm{Bc}$ & $0,64 \mathrm{Cb}$ & $7,06 \mathrm{Aa}$ & $5,55 \mathrm{Ba}$ \\
\hline СРACT 2 & $33,29 \mathrm{Bc}$ & $46,10 \mathrm{Ab}$ & $18,88 \mathrm{Cb}$ & $33,17 \mathrm{Bc}$ & $43,67 \mathrm{Ab}$ & $14,27 \mathrm{Cb}$ & $0,12 \mathrm{Cc}$ & $2,43 \mathrm{Bc}$ & 4,61 $\mathrm{Aa}$ \\
\hline СРACT 3 & $30,46 \mathrm{Ac}$ & $27,89 \mathrm{Ad}$ & $7,65 \mathrm{Bc}$ & $30,22 \mathrm{Ac}$ & $22,83 \mathrm{Ad}$ & $1,83 \mathrm{Bc}$ & $0,24 \mathrm{Bc}$ & $5,06 \mathrm{Ab}$ & $5,82 \mathrm{Aa}$ \\
\hline Belém IPA-9 & $40,47 \mathrm{Bc}$ & $61,78 \mathrm{Aa}$ & $9,33 \mathrm{Cc}$ & $40,06 \mathrm{Bc}$ & $57,53 \mathrm{Aa}$ & $4,06 \mathrm{Cc}$ & $0,41 \mathrm{Bc}$ & $4,25 \mathrm{Ac}$ & 5,27 Aa \\
\hline CNPH 6400 Chata & $30,39 \mathrm{Bc}$ & $46,25 \mathrm{Ab}$ & $15,96 \mathrm{Cc}$ & $29,48 \mathrm{Bc}$ & $41,50 \mathrm{Ab}$ & $11,91 \mathrm{Cb}$ & $0,91 \mathrm{Bb}$ & $4,75 \mathrm{Ab}$ & $4,05 \mathrm{Aa}$ \\
\hline CNPH 6400 Redonda & $28,44 \mathrm{Bc}$ & $44,78 \mathrm{Ab}$ & $18,61 \mathrm{Cb}$ & $27,62 \mathrm{Bc}$ & $41,53 \mathrm{Ab}$ & $13,61 \mathrm{Cb}$ & $0,82 \mathrm{Cb}$ & $3,25 \mathrm{Bc}$ & $5,00 \mathrm{Aa}$ \\
\hline Crioula Alto Vale & $37,67 \mathrm{Ac}$ & $36,63 \mathrm{Ac}$ & $6,83 \mathrm{Bc}$ & $36,56 \mathrm{Ac}$ & $30,78 \mathrm{Ac}$ & $2,05 \mathrm{Bc}$ & $1,11 \mathrm{Bb}$ & $5,85 \mathrm{Ab}$ & $4,78 \mathrm{Aa}$ \\
\hline Bola Precoce & $32,26 \mathrm{Bc}$ & $44,80 \mathrm{Ab}$ & $16,57 \mathrm{Cc}$ & $31,36 \mathrm{Bc}$ & $42,42 \mathrm{Ab}$ & $11,41 \mathrm{Cb}$ & $0,90 \mathrm{Cb}$ & $2,38 \mathrm{Bc}$ & $5,16 \mathrm{Aa}$ \\
\hline Primavera & $32,04 \mathrm{Bc}$ & $47,58 \mathrm{Ab}$ & $19,95 \mathrm{Cb}$ & $31,64 \mathrm{Bc}$ & $44,55 \mathrm{Ab}$ & $14,29 \mathrm{Cb}$ & $0,40 \mathrm{Cc}$ & $3,03 \mathrm{Bc}$ & $5,66 \mathrm{Aa}$ \\
\hline Régia & $32,43 \mathrm{Bc}$ & $60,49 \mathrm{Aa}$ & $24,13 \mathrm{Ba}$ & $32,03 \mathrm{Bc}$ & $58,91 \mathrm{Aa}$ & $19,97 \mathrm{Ca}$ & $0,40 \mathrm{Bc}$ & $1,58 \mathrm{Bc}$ & $4,16 \mathrm{Ab}$ \\
\hline Brisa & $59,98 \mathrm{Aa}$ & $48,11 \mathrm{Bb}$ & $29,84 \mathrm{Ca}$ & $59,78 \mathrm{Aa}$ & $45,35 \mathrm{Ab}$ & $26,62 \mathrm{Ca}$ & $0,20 \mathrm{Bc}$ & $2,76 \mathrm{Ac}$ & $3,22 \mathrm{Ac}$ \\
\hline Alfa São Francisco & $35,10 \mathrm{Ac}$ & $42,85 \mathrm{Ab}$ & $26,83 \mathrm{Ba}$ & $34,53 \mathrm{Ac}$ & $39,03 \mathrm{Bb}$ & $22,95 \mathrm{Ba}$ & $0,57 \mathrm{Bb}$ & $3,82 \mathrm{Ac}$ & $3,88 \mathrm{Ab}$ \\
\hline Valeouro IPA-11 & $45,89 \mathrm{Ab}$ & $48,25 \mathrm{Ab}$ & $18,64 \mathrm{Bb}$ & $45,62 \mathrm{Ab}$ & $44,17 \mathrm{Ab}$ & $12,46 \mathrm{Bb}$ & $0,27 \mathrm{Cc}$ & $4,08 \mathrm{Bc}$ & $6,18 \mathrm{Aa}$ \\
\hline Média & 36,51 & 43,76 & 17,65 & 35,89 & 39,63 & 12,84 & 0,62 & 4,13 & 4,80 \\
\hline $\mathrm{CV}(\%)$ & & 16,74 & & & 19,16 & & & 26,14 & \\
\hline
\end{tabular}

* Médias seguidas pela mesma letra maiúscula na linha e minúscula na coluna, não diferem estatisticamente pelo teste de Skott-Knott, a 5\% de probabilidade (Means followed by the same capital letter in the line and small in the column did not differ from each othe; Skott-Knott, 5\%).

aplicações (40 e 50 dias após o transplantio).

A colheita foi realizada quando $80 \%$ das plantas se encontravam tombadas, o que dependeu do ciclo de maturação de cada genótipo. Após a colheita os bulbos foram curados ao sol durante seis dias, tendo-se sempre o cuidado de acomodar as plantas, de modo que a parte aérea de uma protegesse o bulbo da planta seguinte. Em seguida procedeu-se o toalete eliminando-se o resto das raízes e parte aérea.

Foram avaliados o peso médio de bulbos comerciais, produtividade total, comercial e não comercial de bulbos. Foram considerados bulbos comerciais aqueles com diâmetro maior que $35 \mathrm{~mm}$ (Brasil, 1995).

O delineamento experimental utilizado foi blocos casualizados completos, com 18 tratamentos e três repetições. Os tratamentos corresponderam aos genótipos de cebola CNPH 6415, CNPH 6047, CNPH 6244, CNPH 6400 chata, CNPH 6400 redonda, CPACT 1 , CPACT 2, CPACT 3, Granex 429,
Belém IPA 9, BRS Cascata, Crioula Alto Vale, Bola Precoce, Primavera, Régia, Valeouro IPA-11, Brisa e Alfa São Francisco (Tabela 1). Cada unidade experimental foi composta por quatro fileiras de 50 plantas, espaçadas de $15 \mathrm{~cm}$ entre linhas e $10 \mathrm{~cm}$ entre plantas, com área total de $3 \mathrm{~m}^{2}$ por parcela.

Os dados foram submetidos a análises de variância isoladas para cada experimento, procedendo-se em seguida à análise conjunta dos experimentos. As médias foram comparadas pelo teste de ScottKnott, 5\% de probabilidade com o auxílio do programa Sisvar (Ferreira, 2000).

\section{RESULTADOS E DISCUSSÃO}

Por meio da análise conjunta verificou-se efeito significativo da interação genótipos $\mathrm{x}$ locais para todas as características de rendimento. Com exceção da produtividade não comercial de bulbos, as maiores médias gerais foram obtidas no experimento de Petrolina, sendo a produção comercial $10 \%$ superior à obtida em Mossoró e 209\% supe- rior à obtida em Juazeiro (Tabela 2). Isso deve-se, provavelmente, ao fato da maioria dos genótipos já serem cultivados na região, e consequentemente mais adaptados ao local de cultivo.

No experimento realizado em Mossoró, o genótipo Brisa apresentou as maiores produtividades total e comercial (59,98 e 59,78 $\left.\mathrm{t} \mathrm{ha}^{-1}\right)$. Esses rendimentos foram aproximadamente $160 \%$ acima da média regional $\left(23,0 \mathrm{t} \mathrm{ha}^{-1}\right)$, evidenciando-se boa adaptação do mesmo à região de avaliação (Tabela 2). $\mathrm{O}$ genótipo Brisa foi desenvolvido após seis ciclos de seleção em população oriunda do cruzamento das cultivares Roxa IPA-3 e Texas Grano 1015Y, e é especialmente recomendada para o cultivo no Nordeste brasileiro, preferencialmente a partir do mês de abril (Empresa Pernambucana de Pesquisa Agropecuária, s.d.).

No município de Mossoró e regiões circunvizinhas, a cebola é cultivada de maio a setembro, logo após o período das chuvas, predominando a cultivar Texas Grano 502, irrigada por 
Tabela 3. Peso médio de bulbos comerciais de 18 genótipos de cebola, cultivados em Mossoró, Petrolina e Juazeiro (Average value of commercial bulbs of 18 onion genotypes cultivated in Mossoró, Petrolina and Juazeiro). Mossoró, UFERSA, 2004.

\begin{tabular}{lccc}
\hline \multirow{2}{*}{ Genótipos } & \multicolumn{3}{c}{ Peso médio de bulbo comercial (g) } \\
\cline { 2 - 4 } & Mossoró & Petrolina & Juazeiro \\
\hline CNPH 6415 & $83 \mathrm{Aa}$ & $97 \mathrm{Ac}$ & $81 \mathrm{Aa}$ \\
CNPH 6047 & $76 \mathrm{Ba}$ & $121 \mathrm{Ab}$ & $82 \mathrm{Ba}$ \\
Granex 429 & $95 \mathrm{Ba}$ & $139 \mathrm{Aa}$ & $106 \mathrm{Ba}$ \\
CNPH 6244 & $75 \mathrm{Aa}$ & $68 \mathrm{Ad}$ & $58 \mathrm{Ab}$ \\
BRS Cascata & $83 \mathrm{Aa}$ & $101 \mathrm{Ac}$ & $37 \mathrm{Bb}$ \\
CPACT 1 & $81 \mathrm{Ba}$ & $105 \mathrm{Ac}$ & $58 \mathrm{Bb}$ \\
CPACT 2 & $74 \mathrm{Ba}$ & $106 \mathrm{Ac}$ & $69 \mathrm{Ba}$ \\
CPACT 3 & $88 \mathrm{Aa}$ & $74 \mathrm{Ad}$ & $47 \mathrm{Bb}$ \\
Belém IPA-9 & $72 \mathrm{Ba}$ & $138 \mathrm{Aa}$ & $71 \mathrm{Ba}$ \\
CNPH 6400 Chata & $76 \mathrm{Ba}$ & $116 \mathrm{Ab}$ & $71 \mathrm{Ba}$ \\
CNPH 6400 Redonda & $79 \mathrm{Aa}$ & $92 \mathrm{Ac}$ & $77 \mathrm{Aa}$ \\
Crioula Alto Vale & $63 \mathrm{Aa}$ & $79 \mathrm{Ad}$ & $57 \mathrm{Ab}$ \\
Bola Precoce & $66 \mathrm{Ba}$ & $105 \mathrm{Ac}$ & $74 \mathrm{Ba}$ \\
Primavera & $71 \mathrm{Ba}$ & $108 \mathrm{Ac}$ & $80 \mathrm{Ba}$ \\
Régia & $92 \mathrm{Ba}$ & $138 \mathrm{Aa}$ & $92 \mathrm{Ba}$ \\
Brisa & $86 \mathrm{Ba}$ & $128 \mathrm{Aa}$ & $103 \mathrm{Ba}$ \\
Alfa São Francisco & $84 \mathrm{Aa}$ & $107 \mathrm{Ac}$ & $96 \mathrm{Aa}$ \\
Vale Ouro IPA 11 & $64 \mathrm{Ba}$ & $116 \mathrm{Ab}$ & $79 \mathrm{Ba}$ \\
\hline Média & 78 & 108 & 74 \\
\hline CV(\%) & 16,54 & 10,28 & 22,20 \\
\hline
\end{tabular}

* Médias seguidas pela mesma letra maiúscula na linha e minúscula na coluna, não diferem estatisticamente pelo teste de Skott-Knott, a 5\% de probabilidade (Means followed by the same capital letter in the line and small in the column did not differ from each othe; SkottKnott, 5\%).

gotejamento e com aplicação de fertilizantes via água.

Os genótipos Valeouro IPA-11, CNPH 6244, CNPH 6047 revelaram comportamento intermediário com produtividade total variando de 45,89 a 51,53 t ha $^{-1}$ e comercial de 45,62 a 51,37 t ha ${ }^{-1}$. Os demais genótipos tiveram desempenho inferior, com destaque para o CPACT 1, que apresentou as menores produtividades total $\left(25,09 \mathrm{t} \mathrm{ha}^{-1}\right)$ e comercial (24,45 t ha') (Tabela 2). 'BRS Cascata’ expressou a maior produção não comercial (2,02 t ha $\left.{ }^{-1}\right)$, correspondendo a aproximadamente $6,7 \%$ da produtividade total desse genótipo.

Em Petrolina, os genótipos Belém IPA-9 e Régia foram superiores aos demais, apresentando, respectivamente, produtividades total de 61,78 e 60,49 t ha $^{-1}$ e comercial de 57,53 e 58,91 $\mathrm{t} \mathrm{ha}^{-1}$ (Tabela 2). Esses rendimentos foram superiores à média de produtividade da região e dos obtidos por Costa et al. (1997) e Candeia et al. (2001). Os genótipos CNPH 6047, CNPH 6400 Chata, CNPH 6400 Redonda, CPACT 2, Granex 429, Bola Precoce, Primavera, Valeouro IPA-11, Brisa e Alfa São Francisco tiveram comportamento intermediário com produtividades total e comercial de 42,85 a $51,02 \mathrm{t} \mathrm{ha}^{-1} \mathrm{e}$ de 39,03 a 48,01 $\mathrm{t} \mathrm{ha}^{-1}$, respectivamente. A maior produtividade conseguida em Petrolina prova que a maioria desses genótipos em teste adapta-se bem a essa região de cultivo. Os genótipos $\mathrm{CNPH}$ 6415 e CPACT 1 apresentaram produções de bulbos não comerciais superiores aos demais, sendo respectivamente de 7,51 e 7,06 t ha-1. Esses valores são relevantes, pois representam aproximadamente $20 \%$ da produtividade desses genótipos.

Em Juazeiro, os desempenhos de todos os genótipos ficaram abaixo da média de produtividade da região e também foram inferiores aos obtidos nos experimentos de Mossoró e Petrolina (Tabela 2). Como possíveis fatores responsáveis podem ser destacados o ele- vado $\mathrm{pH}$ do solo da área experimental, o que provavelmente afetou a disponibilidade de alguns nutrientes essenciais para as plantas, uma vez que para as condições de cultivo da cebola a faixa adequada de $\mathrm{pH}$ situa-se entre 6,0 e 6,6; a textura do solo mais argilosa, visto que solo pesado dificulta a formação de bulbos, além de deformá-los, aumentando o número de bulbos "charutos” (Fontes, 1998); e a incidência maior de pragas, como tripes e mosca-minadora e doenças principalmente mancha-purpura ( $\mathrm{Al}$ ternaria porri) e queima das pontas (Botritis sp.), verificadas durante a condução do experimento, podem também ter sido determinantes para o baixo rendimento.

Os genótipos Granex 429, Brisa, Alfa São Francisco e Régia, destacaramse dos demais com produtividade total de 29,$85 ; 29,84 ; 26,83$ e 24,13 t ha $^{-1}$, respectivamente, e comercial de 27,91 ; 26,62; 22,95 e 19,97 tha $\mathrm{t}^{-1}$ nessa mesma ordem (Tabela 2). Os genótipos CNPH 6400 Redonda, Valeouro IPA-11, CPACT 2, CNPH 6047, Primavera e CNPH 6415 apresentaram comportamento intermediário com produtividade total entre 18,61 e 22,57 t ha-1. Além desses genótipos, o 'Bola Precoce' e CNPH 6400 Chata também apresentaram comportamento intermediário para produtividade comercial. Os rendimentos desse grupo de genótipos variaram de 11,41 a 18,24 t ha-1 (Tabela 2). Os genótipos Crioula Alto Vale, CPACT 3, Belém IPA-9, BRS Cascata, CPACT 1, CNPH 6244, CNPH 6400 Chata e Bola Precoce, apresentaram as menores produtividades totais, entre 6,83 e 16,57 t ha $^{-1}$. Para a produtividade comercial, apenas os genótipos CNPH 6244, CPACT 1, BRS Cascata, Belém IPA-9, CPACT 3 e Crioula Alto Vale tiveram comportamento inferiores.

Os rendimentos totais máximos obtidos neste trabalho foram superiores aos apresentados por Araújo et al. (2004) que obtiveram produtividades totais de 23,96 t ha-1, com o genótipo Superex sobressaindo-se dos demais entre os avaliados na Bahia. Porém, as médias obtidas neste trabalho foram inferiores às obtidas por Costa et al. (2003), que alcançaram produtividades totais de 74,74 tha ${ }^{-1}$ com o genótipo TPC-91923. 
Resende et al. (2004), avaliando genótipos de cebola em Juazeiro, alcançaram produtividades totais variando de 19,10 a 45,11 t ha-1.

Desdobrando-se a interação local dentro de genótipos, verifica-se que, com base na produtividade comercial, os genótipos CNPH 6244 e Brisa, apresentaram melhor desempenho em Mossoró. No entanto, CNPH 6415, CNPH 6047, Granex 429, BRS Cascata, CPACT 1, CPACT 3, Crioula Alto Vale, Alfa São Francisco e Valeouro IPA 11, não diferiram estatisticamente em Mossoró e Petrolina, mas foram superiores a Juazeiro. CPACT 2, Belém IPA 9, CNPH 6400 Chata, CNPH 6400 Redonda, Bola Precoce, Primavera e Régia apresentaram melhor desempenho em Petrolina em relação à Mossoró e Juazeiro (Tabela 2).

Para o peso médio de bulbo não houve diferença estatística entre os genótipos avaliados em Mossoró, porém houve uma variação de 63 g (Crioula Alto Vale) a 95 g (Granex 429), com média de 78 g. De acordo com Silva et al. (1991) os bulbos com peso entre 80 e 100 g, têm a preferência do consumidor, que adotaram essa como uma das características de maior valor comercial (Tabela 3). Em Petrolina o peso variou de 68 a 139 g, sendo os genótipos Brisa, Régia, Granex 429 e Belém IPA 9 os que apresentaram os maiores pesos. Tais resultados estão dentro da faixa obtida por Leite et al. (2005), situada entre 86 a 160 g/bulbo, em experimento realizado na mesma região. Os menores pesos médios observados foram para os genótipos CNPH 6244, CPACT 3 e Crioula Alto Vale (Tabela 3).

Em Juazeiro, houve diferença estatística entre os genótipos para o peso médio de bulbos. O ‘Granex 429' e ‘Brisa' apresentaram os maiores valores embora não tenham diferido de $\mathrm{CNPH}$ 6415, CNPH 6047, CPACT 2, Belém IPA-9, CNPH 6400 Chata, CNPH 6400 Redonda, Bola Precoce, Primavera, Régia, Alfa São Francisco e Valeouro IPA-11 (Tabela 3). Considerando-se que bulbos com 80 a 100 g são os preferi- dos pelos consumidores, apenas os genótipos CNPH 6415, CNPH 6047, Granex 429, Primavera, Régia, Brisa e Alfa São Francisco apresentaram-se dentro desta faixa de peso.

Desdobrando-se a interação local dentro de genótipos, verifica-se que os genótipos CNPH 6244, Granex 429, CPACT 1, CPACT 2, Belém IPA 9, CNPH 6400 Chata, Bola Precoce, Primavera, Régia, Brisa e Valeouro IPA 11 apresentaram maior peso de bulbo em Petrolina; entretanto, não houve diferença estatística entre Mossoró e Juazeiro. BRS Cascata e CPACT 3 foram estatisticamente iguais em Mossoró e Petrolina, porém superiores a Juazeiro. Para os demais genótipos não houve diferença significativa entre os locais de avaliação (Tabela 3).

Considerando a produtividade comercial, os genótipos Brisa em Mossoró, Belém IPA 9 e Régia em Petrolina e Granex 429, Régia, Brisa e Alfa São Francisco em Juazeiro apresentaram os melhores desempenhos, destacando-se como alternativas para cultivo no período de realização do trabalho nessas regiões. Entretanto, aqueles genótipos que tiveram comportamentos intermediários não deverão ser descartados, pois apesar de inferiores, as produtividades foram na sua maioria, maiores que as produtividades médias das regiões em estudo.

\section{REFERÊNCIAS}

ARAÚJO JF; COSTA ND; LIMA MAC; PEDREIRA CM; SANTOS C; LEITE WM. 2004. Avaliação de genótipos em cultivo orgânico. In: CONGRESSO BRASILEIRO DE OLERICULTURA, 44. Resumos... Campo Grande: SOB (CD-ROM).

BRASIL - Ministério da Agricultura, Abastecimento e Reforma Agrária. Portaria n.529 de 18 ago. 1995. Diário Oficial da República Federativa do Brasil, Brasília, 1 set. 1995, Seção 1, p.13513.

CANDEIA JA; MENEZES JT; MENEZES D; MARANHÃO EAA; FRANÇA JGE. 1997. Cultivar de cebola Valeouro IPA-11. In: CONGRESSO BRASILEIRO DE OLERICULTURA, 37. Resumos... Manaus: SOB (CD-ROM).
CANDEIA JA; WANDERLEY LJG; MENEZES JT; MENEZES D. 1987. Cultivar de cebola “Pêra Norte IPA-7”. In: CONGRESSO BRASILEIRO DE OLERICULTURA, 27. Resumos... Brasília: SOB.

CANDEIA JA; MENEZES D; SANTOS VF; MENEZES JT. 2001. Desempenho agronômico de cultivares de cebola em Pernambuco. In: CONGRESSO BRASILEIRO DE OLERICULTURA, 41. Resumos...Brasília: SOB (CD-ROM).

CAVALCANTI FJA. 1988. Recomendação de adubação para o estado de Pernambuco: $2^{a}$ aproximação. Recife: IPA. 198 p.

COSTA ND; RESENDE GM; DIAS CS. 1997. Avaliação de cultivares de cebola no trópico Semi-Árido Brasileiro. In: CONGRESSO IBEROAMERICANO DE CIÊNCIAS HORTÍCOLAS, 2. Resumos... Vilamoura: APH-SECH.

COSTA ND; RESENDE GM; DIAS RCS. 2000. Avaliação de cultivares de cebola em PetrolinaPE. Horticultura Brasileira. 18: 57-60.

COSTA ND; SANTOS CAF; FARIA CMB; LIMA MAC; ASSIS JS. 2003. Avaliação de genótipos de cebola suave no Submédio São Francisco. In: CONGRESSO BRASILEIRO DE OLERICULTURA, 43. Resumos...Recife: SOB (CD-ROM).

Empresa Pernambucana de Pesquisa Agropecuária. Cultivar de cebola de pungência moderada. Recife: BNB, [s.d.]. (Folder, Brisa IPA-12).

FAO - Agricultural production, primary crops. 2005, 30 de junho. Disponível em: http:// www.fao.org. Acessado em 30 de junho de 2005

FERREIRA DF. 2000. Sistemas de análises estatísticas, 3.1. Lavras: UFLA.

FONTES PCR. 1998. Cultura da cebola. Viçosa: UFV. 40 p.

IBGE - Instituto Brasileiro de Geografia e Estatísticas. 2005, 18 de maio. Censo Agropecuário. Disponível em: http:// www.agricultura.gov.br. Acessado em 18 de maio de 2005.

LEITE WM; COSTA ND; SANTOS CAF; RESENDE GM; SANTOS GM; FARIA CMB; PINTO JM. 2005. Comportamento de cultivares de cebola no Vale do São Francisco. In: CONGRESSO BRASILEIRO DE OLERICULTURA, 45. Resumos...Forlaleza: SOB (CD-ROM).

RESENDE GM; COSTA ND; SANTOS GM; SANTOS CAF; LEITE WM. 2004. Caracterização produtiva de genótipos de cebola em Vertissolo no Vale do São Francisco. In: CONGRESSO BRASILEIRO DE OLERICULTURA, 44. Resumos...Campo Grande: SOB (CD-ROM).

SILVA E; TEIXEIRA LAJ; AMADO TJC. 1991. The increase in onion production in Santa Catarina State, South Brasil. Onion Newsletter for the Tropics 3: 7-9. 